\title{
Semi Operational Prediction of the Dead Sea Evaporation-A Synoptic Systems Approach
}

\author{
Eyal Ilotoviz1, Haim Shafir², Philipp Gasch33, Pinhas Alpert ${ }^{2 *}$ \\ ${ }^{1}$ Department of Atmospheric Sciences, The Hebrew University of Jerusalem, Jerusalem, Israel \\ ${ }^{2}$ Department of Geosciences, Tel Aviv University, Tel Aviv, Israel \\ ${ }^{3}$ Institute of Meteorology and Climate Research, Karlsruhe Institute of Technology, Karlsruhe, Germany \\ Email: ${ }^{*}$ pinhas@post.tau.ac.il
}

Received 11 June 2015; accepted 14 September 2015; published 17 September 2015

Copyright (C) 2015 by authors and Scientific Research Publishing Inc.

This work is licensed under the Creative Commons Attribution International License (CC BY).

http://creativecommons.org/licenses/by/4.0/

(c) (i) Open Access

\section{Abstract}

The predictability of pan evaporation and air temperature in the southern part of the Dead-Sea region (Sdom) was investigated according to two approaches, prediction by mesoscale models and with the aid of synoptic classification. First, the predicted temperature, wind speed and relative humidity that directly affect the evaporation are obtained from the WRF mesoscale model predictions. Predictions according to multi-linear regression equations and a Penman-Monteith approach were also validated against observations in Sdom. The WRF model predicts the temperature reasonably well. However, the wind speed and relative humidity predictions were found to be very poor. The unique approach in this paper is employing a semi-objective synoptic systems classification according to the global GFS model. Relationships were defined between the 19 Eastern Mediterranean's (EM) synoptic systems and the Sdom evaporation, temperature, wind speed and relative humidity. A monthly evaluation was performed for each of the systems and the semi-objective prediction was verified by the semi-objective classification. Since some synoptic systems affect the evaporation and temperature similarly, the 19 synoptic systems were grouped into seven clusters, each containing systems with similar evaporation and temperature records. This method has yielded a significant improvement in the daily prediction of evaporation and temperature. Semi-objective definitions for the synoptic systems were performed for the ranges of 12 - 132 hours. The synoptic system approach succeeded in the prediction of the evaporation and temperature changes in Sdom for a few days in advance. The predictability skill for the $\mathbf{1 2}$ hour forecast achieved about $80 \%$ of success, dropping to $70 \%$ at 36 hours. For 60 to 132 hours the prediction stabilized at a skill of $60 \%$.The method presented here is a new attempt to predict meteorological parameters by using a synoptic classification approach in the Dead-Sea area where even high-resolution mesoscale modeling forecasts are not very successful.

*Corresponding author.

How to cite this paper: Ilotoviz, E., Shafir, H., Gasch, P. and Alpert, P. (2015) Semi Operational Prediction of the Dead Sea Evaporation-A Synoptic Systems Approach. Journal of Water Resource and Protection, 7, 1058-1074. 


\section{Keywords}

\section{Synoptic Classification, Dead-Sea Evaporation, Eastern Mediterranean}

\section{Introduction}

The Dead-Sea (DS) is a unique place on Earth for several reasons. It is located at the lowest spot of the earth's surface $(-429 \mathrm{~m})$, its water is the densest and saltiest of any natural water body, and staying there can help cure some illnesses [1]. The local climate of the DS is equally unique and consists of much complexity. The DS breeze influences the wind, temperature, relative humidity and evaporation. First, the local sea breeze starts blowing in the morning until late afternoon hours, while the land breeze starts at night until the early morning hours [2]-[5]. Second, the Mediterranean breeze penetrates the Dead-Sea Valley in the late afternoon hours [3] [6], mainly in spring and summer [7]. Third, strong anabatic and katabatic winds are blowing due to the steep and complex topography over the region [4]. Fourth, wadis can affect the speed and direction of winds [8]. [9] have shown that the Jordan Valley and the DS area have a high index of mesoscale activity (I > 1), even during winter when in almost all Israeli locations this index drops below 1. The climate of the DS is very hot and dry with very low precipitation throughout the year with an annual total of $20-50 \mathrm{~mm} / \mathrm{y}$.

The evaporation in the southern Dead-Sea (Sdom station) is an important factor in the local climate and for the local potash industry. The evaporation rate in this area is very high in respect to other places on Earth. The concentrated salts of the lake and the arid climate help the DS factories to manufacture potash, bromine, magnesium and other minerals through the natural high evaporation which makes the production process efficient. Hence, the short-range $(1-4 \mathrm{~d})$ prediction of the evaporation rate and the temperature are important for the planning of the production processes. Knowledge of the daily change of evaporation rate several days ahead can therefore improve the production process by a more efficient management of the DS water flow from the north to the evaporation ponds.

Several earlier works deal with the evaporation in Sdom. [5] reported on pan evaporation increase in Sdom from about $350 \mathrm{~cm} / \mathrm{y}$ in the 1960s to about $400 \mathrm{~cm} / \mathrm{y}$ in the 1990s. They explained this dramatic evaporation increase by the local climate change following the lake drying. As a result of the lake drying the local sea breeze was weakened, thus, the temperature increased and the relative humidity decreased causing an evaporation increase in Sdom. Another factor in the pan evaporation increase is the increase of the DS concentrate salts and the water density as a result from the lake drying which reduces the DS water evaporation. This reduction decreases the water vapor concentration in the surrounding air masses, thus increasing the pan evaporation rate in Sdom [10]. [11] found a local climate change which was attributed to the salinity increase in the DS. [6] has shown that the more recent climate changes over the DS (since 1990 ) could be partly explained by larger-scale variations, i.e. the increase of the hot synoptic systems in the region. They suggested that while the local effect of the lake drying was the dominant factor in the DS increased evaporation in the 1970-1990, the effect of the global changes has become dominant since the 90s.

Several researches deal with the synoptic system change in the Eastern Mediterranean (EM). [12] reported that the frequency of the dry Red Sea trough (RST) systems nearly doubled since the 1960s from 50 - 60 to about $100 \mathrm{~d} / \mathrm{y}$. [6] also pointed to a significant increase of the frequency of the hottest summer system, i.e. the Weak Persian Trough (WPT). Its number increased due to the decrease of other relatively cooler summer systems, i.e. the Medium Persian Trough (MPT) and the Deep Persian Trough (DPT). The frequency of the WPT has increased from 35 days per year in the 1964-1974 to 49 during 1996-2005, while the frequencies of the MPT and DPT reduced from 56 to 43 and from 13 to $5 \mathrm{~d} / \mathrm{y}$, respectively. [6] has quantified the pan evaporation increase in Sdom due to these synoptic changes.

Several attempts were made to predict evaporation with different methods [13]-[15]. This paper studies the prediction of evaporation in Sdom in relation to the synoptic systems in the EM, but focusing on a timescale of several days. The ability to predict changes in evaporation and temperature several days ahead can be used to increase the efficiency of several mineral production processes. The objective of this work is to explore methods to predict the average daily pan evaporation and the relevant variables that influence evaporation in Sdom. The methodology of this study can be seen in Figure 1. The synoptic systems classification proposed by [12] is employed here to predict evaporation some days ahead. 


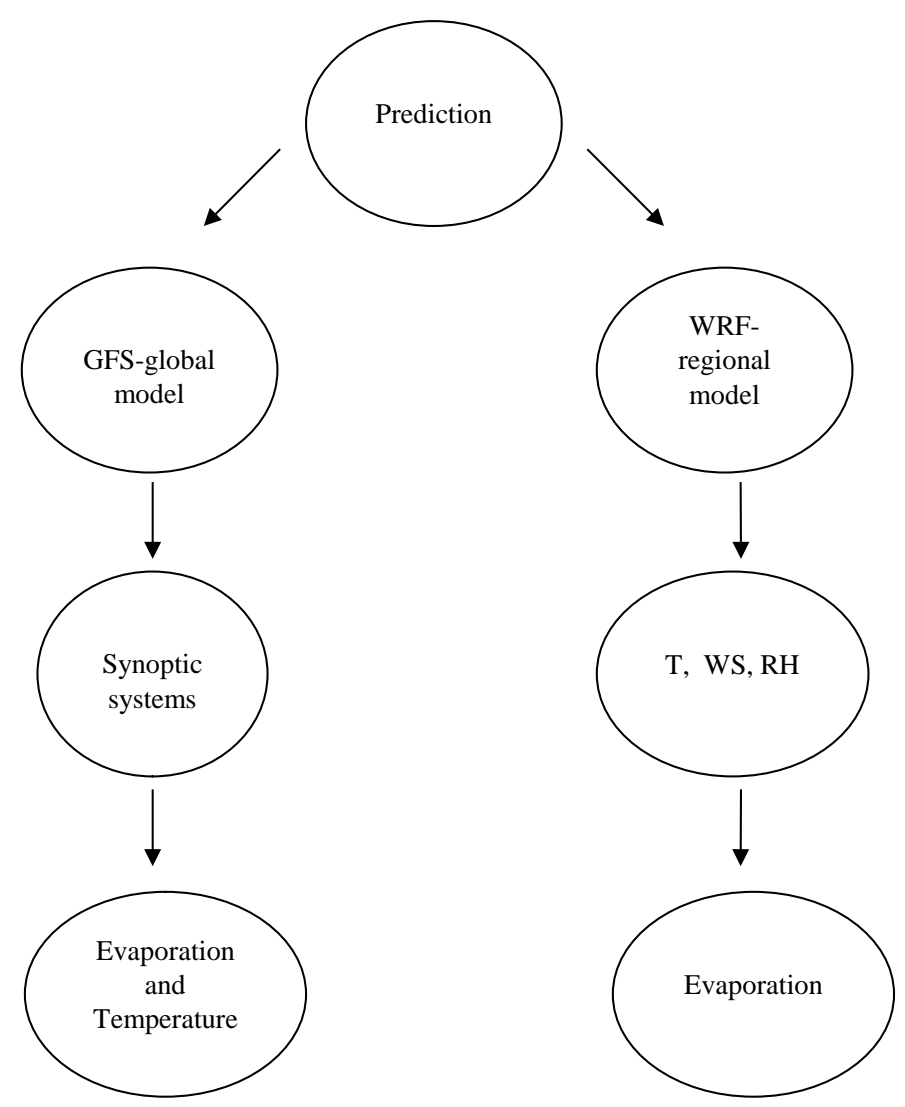

Figure 1. Sketch of the two approaches for predicting the Dead-Sea Sdom evaporation; on the left side the synoptic system approach while on right-side the direct approach based on the WRF mesoscale model predictions.

Several earlier studies used an approach similar to ours by using similar methods based on the [12] synoptic classification. [16] analyzed the relation of 996 dust days in Israel with the synoptic type's classification. They found that systems contributing the most were winter lows, Red Sea Troughs and highs. [17] examined the ability of the inter-annual variability in the occurrence of some synoptic systems to predict the $850 \mathrm{hPa}$ temperature in Israel for summer and winter. [18] used the same method as [17] to investigate the factors governing the precipitation in the EM. The inter-annual variations of rainfall were found to be well explained by the synoptic types, and the occurrences of Cyprus lows were highly correlated with rainfall [19]. [20] also used a similar method to estimate the future levels of air pollutants' concentrations based on the same synoptic classification. [6] investigated the average daily evaporation in Sdom according to the same synoptic classification. In addition, they quantified the relative contribution of each synoptic system to the Sdom annual evaporation, which was employed here but on a monthly scale. In this study, there was an attempt to predict the temperature, relative humidity and wind speed from Sdom. These three variables have a strong impact on the evaporation. Forecasts were made by using the Weather Research and Forecasting Model [21].

The uniqueness of this study is the employment of a semi-operational classification of the synoptic systems for several days of weather prediction over the very complex DS topography. This approach was adopted following the examination of alternative real-time prediction methods to be described next.

\section{Multi Linear Regression and the Penman-Monteith Equations for the Prediction of Dead-Sea Evaporation}

Multi linear regression equations were tested for Sdom during 1964-2009 (10,679 days). Many options were checked including combinations of hourly values of wind, temperature and humidity. The highest correlation was reached with daily averages of the temperature, wind speed and relative humidity as the independent variables at three hours (6:00, 12:00, and 18:00 UTC). The pan evaporation is the dependent variable in the regres- 
sion equation, and the correlation achieved reached $R=0.89$. A similar correlation value $(R=0.88)$ was found by the Penman-Monteith's approach tested for the 1964-2005 period. For the Penman-Monteith's calculations algorithms developed by [22] for daily evaporation were employed. [23] also used the Penman's approach to calculate the Lake Kinneret daily evaporation, and found it in good agreement with the measured pan evaporation. In another application of the Penman-Monteith approach, [24] deals with validation of land surface observations from a desert site and from a plantation. Model evapotranspiration was validated with two PenmanMonteith estimates based on the observations.

The same was done for the sensible heat flux which was calculated as a residual of observed energy balance terms and latent heat flux estimate from the Penman-Monteith approach. The study shows that evaporation calculated through the Penman-Monteith approach in arid regions can in general be reproduced through simulations.

The multi linear regression and the Penman-Monteith methods were tested for each of the seasons, and the correlations were similar. The simple seasons' definition was adopted, i.e. December-February, March-May, June-August and September-November for winter, spring, summer and autumn, respectively. The new synoptic definition as suggested by [25] was not applied here. In both, the multi linear regression and the Penman-Monteith method, we got the highest correlations in the transition seasons, while the lowest correlation was found in the summer. This is probably due to the relatively small inter-daily evaporation variation in summer as compared to the larger variability of the dominant factors in the other seasons. In addition, in summer, the radiation changes due to aerosols concentration, however, the radiation variability was not included in the multi linear regression and the turbidity was not taken into account in the solar radiation for the PM equation. Obviously, the actual solar radiation reaching the evaporating surface depends on the turbidity of the atmosphere (and the presence of clouds which are very little in the DS area) which reflects and absorbs parts of the radiation.

These two methods, i.e. multi linear regression and the PM, were tested in real-time by employing the WRF model predictions (horizontal interval of $1.3 \mathrm{~km}$ and vertical resolution of 31 sigma layers) for the temperature, wind speed and relative humidity in the nearest grid-point to Sdom. The model was validated against Sdom observations for a period of 29 days from Jan-Mar 2010, and the range of the forecast was 24 - 72 hours. Correlation results (Table 1), indicate that the model predicts the temperature quite well. However, the wind speed and the relative humidity short-range predictions in the Dead-Sea Valley (Sdom) achieve quite low skill correlations. The significance-levels for the correlations were calculated following the T-test, and it was found that the temperature significance-level is very high; however the RH and wind speed correlations are not significant except for the $48 \mathrm{~h}$ predictions. Because these parameters are crucial for the evaporation prediction the synoptic approach was adopted as described next.

\section{Method of Analysis}

\subsection{Semi-Objective Classification for Daily Synoptic Systems}

[12] suggested a semi-objective classification for the daily synoptic systems in the eastern Mediterranean (EM). They provided the synoptic classification for every day at 12:00 UTC for the years of 1948-2004. Recently, the classification was extended until 2015. The EM region was defined by the square of $27.5^{\circ} \mathrm{N}, 30^{\circ} \mathrm{E}$ to $37.5^{\circ} \mathrm{N}$, $40^{\circ} \mathrm{E}$, with horizontal intervals of $2.5^{\circ}$ which totals up to 25 grid points. The data was downloaded from the NCEP-NCAR reanalysis site (http://www.cdc.noaa.gov/). The synoptic systems classification was based on four fields: geopotential height $(\mathrm{H})$, temperature $(\mathrm{T})$ and two horizontal wind components (U and V), all at $1000 \mathrm{hPa}$. Hence, the four fields at 25 grid points yield 100 variables for each day. [12] defined 19 classes of EM synoptic systems (Appendix 1). The 19 systems belong to 6 larger groups that are described by [12]. This classification

Table 1. Correlations and their significance levels between the WRF model predictions and observations of T, RH and wind speed (WS) for 24,48 and $72 \mathrm{~h}$.

\begin{tabular}{ccccccccccc}
\hline $\begin{array}{c}\text { Forecast } \\
\text { (hours) }\end{array}$ & $\begin{array}{c}\mathrm{T}\left({ }^{\circ} \mathrm{C}\right) \\
\mathrm{R}^{2}\end{array}$ & $\begin{array}{c}\mathrm{T}\left({ }^{\circ} \mathrm{C}\right) \\
\mathrm{R}\end{array}$ & $\begin{array}{c}\mathrm{T} \mathrm{Sig} \\
\text { at }\end{array}$ & $\begin{array}{c}\mathrm{RH}(\%) \\
\mathrm{R}^{2}\end{array}$ & $\begin{array}{c}\mathrm{RH}(\%) \\
\mathrm{R}\end{array}$ & $\begin{array}{c}\mathrm{RH} \text { Sig } \\
\text { at }\end{array}$ & $\begin{array}{c}\mathrm{WS}(\mathrm{m} / \mathrm{s}) \\
\mathrm{R}^{2}\end{array}$ & $\begin{array}{c}\text { WS (m/s) } \\
\mathrm{R}\end{array}$ & $\begin{array}{c}\text { WS Sig } \\
\text { at }\end{array}$ \\
\hline 24 & 0.74 & 0.86 & 0.005 & 0.01 & 0.1 & No sig & 0.39 & 0.62 & 0.005 \\
48 & 0.7 & 0.83 & 0.005 & 0.16 & 0.4 & 0.025 & 0.12 & 0.34 & 0.05 \\
72 & 0.69 & 0.83 & 0.005 & 0.02 & 0.15 & No sig & 0.04 & 0.21 & No sig \\
\hline
\end{tabular}


was defined as semi-objective because the 426 daily synoptic systems where defined by a group of meteorological experts, and served as the "training data-base". The minimal Euclidean distance found between any other day and each of these manually classified days has determined the synoptic system of that specific day.

\subsection{Measurements of Meteorological Variables in the Sdom Station}

Sdom station is located in the southern part of the DS ( $\left.31^{\circ} 11^{\prime} \mathrm{N}, 35^{\circ} 23^{\prime} \mathrm{E}\right)$ at an altitude of $390 \mathrm{~m}$ below the sea level. This station is operating since 1951, except for the period 1978-1981.The observations of pan evaporation $\left(\mathrm{mm} /\right.$ day), temperature $\left({ }^{\circ} \mathrm{C}\right)$, wind speed $(\mathrm{m} / \mathrm{s})$ and relative humidity $(\%)$ were measured for the period 1964-2006. The pan evaporation is measured once a day, while the temperature, wind speed and relative humidity are measured three times daily (6:00, 12:00, and 18:00 UTC). Evaporation is measured with a standard US class A pan with $121 \mathrm{~cm}$ diameter, $25.5 \mathrm{~cm}$ deep, resting on an open wooden platform set on the ground and protected by the standard wire net screen of the Israel Meteorological Service. Each variable includes averages of data from the three aforementioned times. The data series of evaporation is the longest when compared to the other variables. The reason for the different sizes of data vectors is the fact that some of the days are missing one or more observation times (of the three daily) or because one of the variables is missing.

\subsection{The Connection between the Synoptic Systems and the Meteorological Variables in Sdom}

The synoptic systems are influencing the EM climate in general, including the DS region. According to the daily synoptic systems classification by [6] [12] has computed the average daily evaporation at Sdom for each system during 1964-2006. Here, this study was extended by computing the connection between all the 19 systems to the Sdom observation for each month. The daily averages of evaporation, temperature, wind speed and relative humidity for each month during 1964-2006 was calculated (Appendixes 2-7). One reason for choosing the monthly scale is the high inter-monthly solar variability. For instance, the RST system shows different daily averages of evaporation in October and November because of the significant solar radiation change. In addition, the frequency of each synoptic system per month determines the weight given in the prediction for each specific system. For instance, the RST is dominant in the autumn season, but its frequency is very low in summer. Therefore, the RST weight for the autumn prediction is much larger. Figures 2-4 show the average daily values of evaporation, temperature and wind speed for the three different types of the RST systems. All the other 16 synoptic

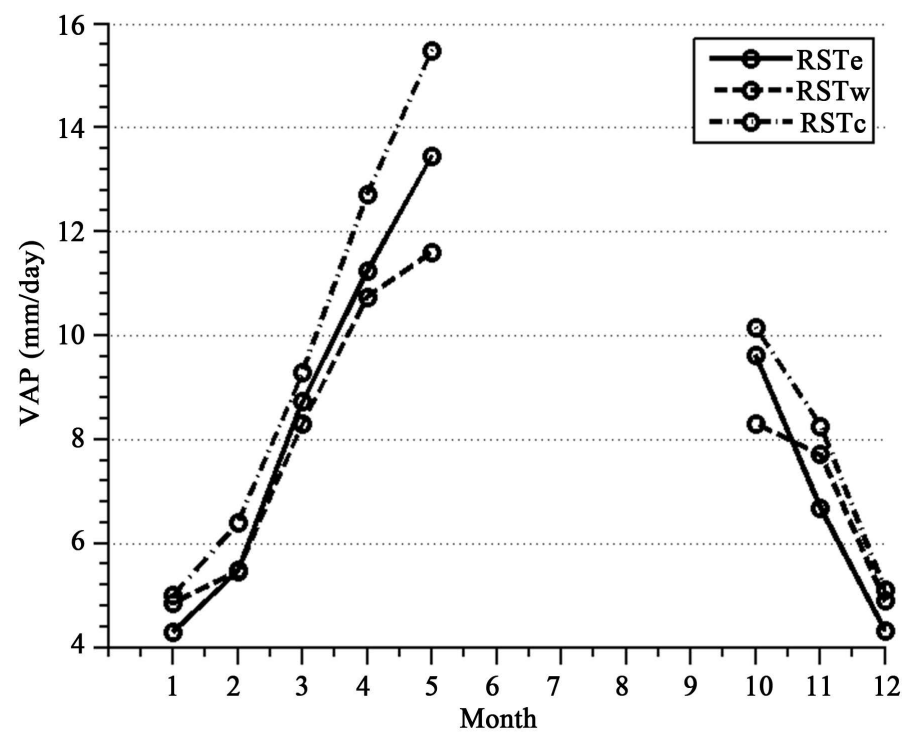

Figure 2. Comparison of the daily average pan evaporation $(\mathrm{mm} / \mathrm{d})$ for each month for the three different RST systems. The systems are the RST with eastern axis (solid line), western axis (dashed line) and central axis (dashed-dotted line). The average daily pan evaporation is based on the period 1964-2006. During May-Sep the RST systems are very rare, and therefore not plotted. 


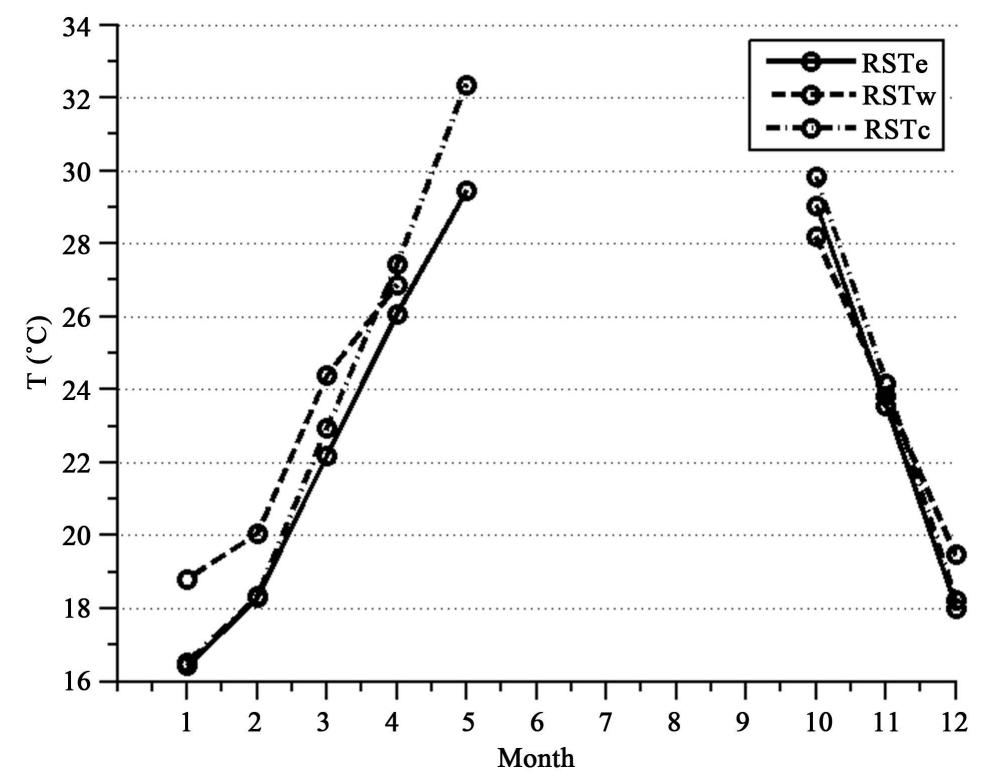

Figure 3. Temperature comparison for the three RST systems. The RST with eastern axis (solid line), western axis (dashed line) and central axis (dash-dot line). The average daily of temperature is based on a very large observational period (19642006).

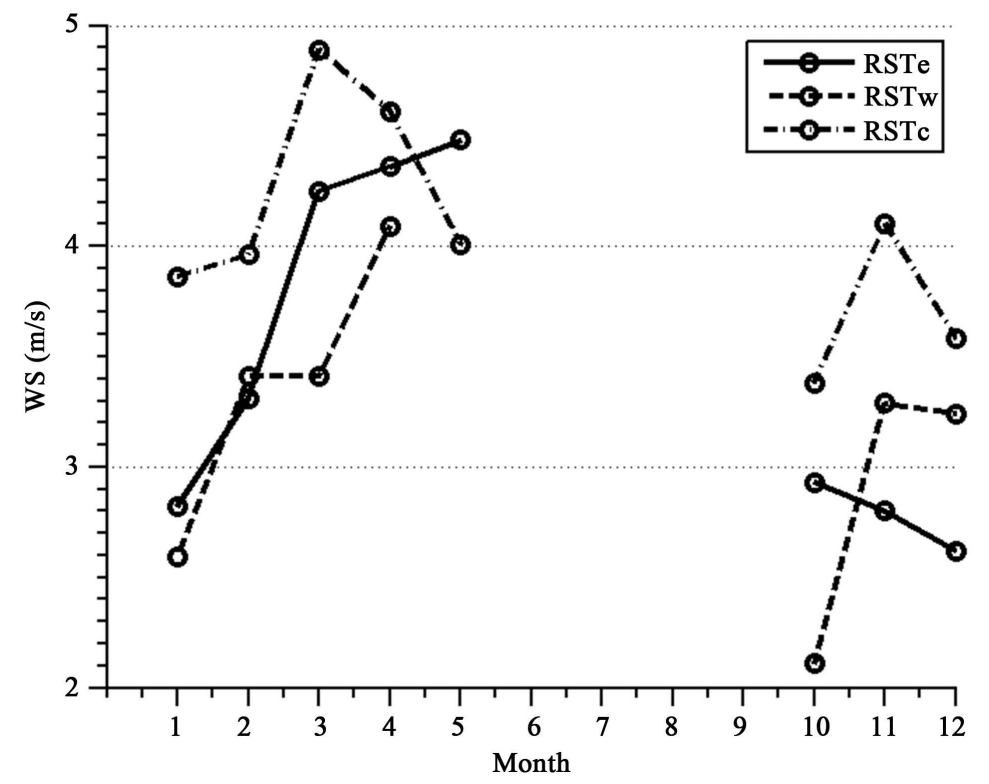

Figure 4. Wind speed (WS) comparison for the three RST systems. The RST with eastern axis (solid line), western axis (dashed line) and c axis (dash-dot line). The daily average of wind speed is based on a very large observational period (1964-2006).

systems were tested as well (Appendixes 2-7). We choose to show the RST example because of its complexity. The same statistics are shown in Figure 5 for the high to the west (HW, in brevity). The HW system influences the EM throughout the year. In contrast, the frequency of the Sharav low system is very low, about once a week in the high spring [26]. The major reason for its low frequency, besides its low natural rate of occurrence is the fact that the Sharav lows move quickly eastward along the North African coastline, sometimes crossing the DS area within a period of less than 1 day [26]. Therefore, the Sharav low appearance over the EM may fall between the noon classifications times (1200 UTC). [25] estimated that about a third of the Sharav lows were passing over the EM at non-sampling times. 


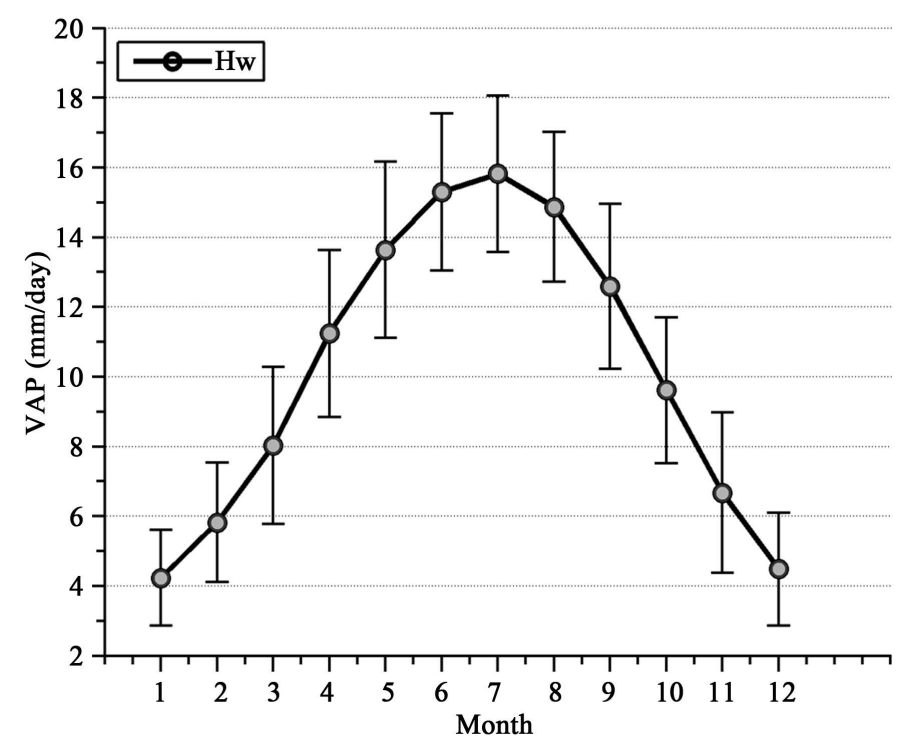

Figure 5. The average daily pan evaporation and its standard deviation for each month. Results are based on the 1964-2006 period for the High to the west (Hw) synoptic system. This synoptic system (Hw) is the only system existing throughout the year, and is shown to illustrate the values that serve as the monthly basis for our forecasting approach.

\subsection{Semi-Objective Predictions of Synoptic Systems (Reforecasts)}

The predictability of the evaporation with the aid of the synoptic systems was tested on the basis of the past, employing the NCEP/NCAR reanalysis. The data was downloaded from the reanalysis site (http://www.cdc.noaa.gov/). The reforecast dataset was based on the 1998 version of the NCEP Medium Range Forecast (MRF) model run with a $\sim 200 \mathrm{~km}$ horizontal interval with 28 vertical sigma levels [27]. The data was available every day from 1979 to present time starting from 0000 UTC initial conditions. The data was tested for four years (2006-2009) which add up to 1435 days. In addition, the prediction was tested for $12 \mathrm{~h} \mathrm{-} 132 \mathrm{~h}$ prediction times with a $24 \mathrm{~h}$ step. The reason for this large step is the synoptic systems classification sampling times, which are currently available only at 1200 UTC. The four variables extracted are H, T, U, and V for 25 grid points at $1000 \mathrm{hPa}$. In the reforecast experiment, the lowest available geopotential height $(\mathrm{H})$ is at the 850 $\mathrm{hPa}$ level. Therefore, the sea level pressure variable was computed through the hypsometric equation for the calculation of $1000 \mathrm{hPa}$ heights. All the resulting predictions were divided into three levels of accuracy:

\subsection{Three Levels of Accuracy for Prediction of the Synoptic System}

\subsubsection{The First Order Accurate Forecast}

This case is defined when the predicted synoptic system exactly fits the analyzed one.

\subsubsection{The Cluster Accurate Forecast}

This case is defined when the predicted system fits the cluster of synoptic system it belongs to. For instance, the major cluster belongs to the summer. This is because of the similar patterns of the PTW, PTM, PTD and HW synoptic systems. In addition, the cluster must have a similar influence on the average daily pan evaporation and temperature. The PT summer systems constitute a very large cluster along with HW. On the other hand, RST systems do not carry similar average evaporation and temperature characteristics. Therefore, they are not considered as a cluster, even if there carry similar synoptic pattern. The improvement of the ability to predict evaporation in Sdom according to 'cluster accurate forecast' is shown in Figure 6 (dashed-dotted line). Furthermore, the improvement for three dominant clusters (total seven clusters) for the full forecast range is shown in Table 2.

\subsubsection{Inaccurate Forecast}

In this third case the forecast of the predicted synoptic system did fit to neither the analyzed system nor to that of the cluster which it belongs to. 


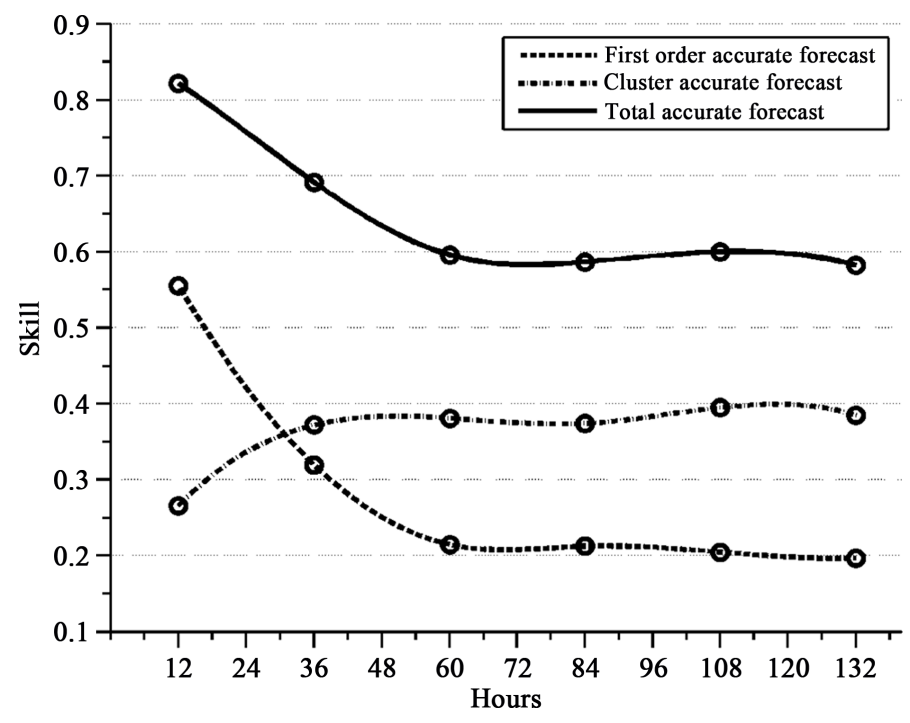

Figure 6. The skill of 12 - 132 h prediction for 2006-2009. Skill of 1 means a $100 \%$ successful prediction. The first order accurate forecast is the dashed line, the cluster accurate forecast is the dashed-dotted line and the total accurate forecast is the solid line. The skill was calculated for the following prediction times: 12, 36, 60, 84, 108 and 132 hours, and was interpolated between the points with a spline function.

Table 2. The "Cluster" forecast: This summary is for the three main clusters (from a total of seven). Each cluster includes the synoptic systems whose influences on evaporation and temperature are very similar. First column: represents the number of the group. Second column: the list of the synoptic systems within the cluster (Appendix 1). Third and fourth columns: minimum and maximum of average evaporation, respectively. Fifth and sixth columns: minimum and maximum of average temperature. Seventh column up to twelfth, the \%-improve of prediction for $12-132$, respectively. The $13^{\text {th }}$ column is the dominant season. Seasons notations are "sum” for summer; "wint” for winter; "aut” for autumn; "spr” for spring.

\begin{tabular}{ccccccccccccc}
\hline Cluster & $\begin{array}{c}\text { Synoptic } \\
\text { systems }\end{array}$ & $\begin{array}{c}\text { Min evap } \\
(\mathrm{mm} / \mathrm{d})\end{array}$ & $\begin{array}{c}\text { Max evap } \\
(\mathrm{mm} / \mathrm{d})\end{array}$ & $\begin{array}{c}\text { Min temp } \\
\left({ }^{\circ} \mathrm{C}\right)\end{array}$ & $\begin{array}{c}\text { Max temp } \\
\left({ }^{\circ} \mathrm{C}\right)\end{array}$ & $\begin{array}{c}12 \mathrm{~h} \\
(\%)\end{array}$ & $\begin{array}{c}36 \mathrm{~h} \\
(\%)\end{array}$ & $\begin{array}{c}60 \mathrm{~h} \\
(\%)\end{array}$ & $\begin{array}{c}84 \mathrm{~h} \\
(\%)\end{array}$ & $\begin{array}{c}108 \mathrm{~h} \\
(\%)\end{array}$ & $\begin{array}{c}132 \mathrm{~h} \\
(\%)\end{array}$ & $\begin{array}{c}\text { Dominant } \\
\text { season }\end{array}$ \\
\hline 1 & $\begin{array}{c}\text { PT-W, PT-M, PT-D, } \\
\text { Hw, CLn-S }\end{array}$ & 14.03 & 14.91 & 32.92 & 34.53 & 19 & 23 & 25 & 25 & 25 & 27 & Sum/Spr \\
2 & $\begin{array}{c}\text { RSTe, Hw, Hc } \\
2\end{array}$ & 7.7 & 8.06 & 22.54 & 23.2 & 5 & 7 & 7 & 6 & 8 & 7 & Aut/Wint/Spr \\
3 & RSTc, Hn & 7.66 & 8.16 & 21.26 & 22.52 & 1 & 2 & 2 & 2 & 1 & 1 & Aut/Wint/Spr \\
\hline
\end{tabular}

The skill was calculated as follows: The skill for the first order accurate forecast was defined as the number of days that were classified as first order accurate forecast divided by the total number (1435 days). The skill for the cluster accurate forecast was defined as number of days classified as cluster accurate forecast divided by the total number (1435 days). The skill for inaccurate forecast was defined similarly.

\section{Results and Discussion}

Exploring the prediction potential of the average daily pan evaporation in the Dead-Sea (Sdom) according to the daily synoptic systems is the primary goal here. Our aim is to investigate the predictability of the daily evaporation at Sdom through large scale predictions of the semi-objective synoptic class employing the previously calculated relationships of these classes with the daily evaporation. The connection between the synoptic systems and the local meteorological variables in Sdom is very important for this kind of prediction. The large climatological dataset shows that we need to analyze each of the 19 EM synoptic systems separately.

In order to predict the pan evaporation changes on a daily scale in Sdom, we examined the daily averages of the evaporation and explained the results with other variables (daily average of temperature, wind speed and relative humidity). The calculations were conducted for each synoptic system for each month for a 42-year period (1964-2006). The standard deviation is also included in the climatological data. The monthly scale reveals some interesting connections between the synoptic systems and the other variables at Sdom. 
The semi-objective prediction of the synoptic systems (synoptic class) was verified by a semi-objective classification for the daily synoptic systems in the period of 2006-2009. The prediction skill of the synoptic systems is shown in Figure 6. The skill was calculated as the fraction in which the semi-objective prediction succeeds to predict the synoptic system that was analyzed according to the semi-objective classification (the fraction is the number of correct days divided by the total number of days between 2006 and 2009). The latter is called "first order accurate forecast (Figure 6)". The contribution of the "cluster accurate forecast" is also shown in Figure 6. The total accurate forecast then is the number of days in which either "first order accurate forecast" or "cluster accurate forecast" is correct divided by the total number of days between 2006 and 2009.

The first order forecast skill decreased dramatically with time limited by the capabilities of the global model. For 12 hours the skill value was $\sim 56 \%$ and from 60 hours up to 132 hours it was stabilized at about $20 \%$ of skill value. Because of this poor success we used a different approach by dividing the synoptic systems to clusters. The cluster forecast skill increased up to 36 hours because of the similar conditions of the synoptic systems which achieve a better prediction than the first order accurate forecast. From 36 hours onward the skill of the cluster was quite stable. In this approach the total accurate forecast. We predict synoptic system and according to the synoptic system, we know the daily pan evaporation from our large statistics (1964-2006)) is the total sum of first order accurate forecast and that of the cluster synoptic systems. The 12-h total skill was above $80 \%$. After 36 hours the skill dropped to $\sim 70 \%$, while for 60 - 132-h it was about $\sim 60 \%$. According to the results, the cluster approach significantly improved the skill. There are seven groups of clusters (three of them are represented in Table 2). The first group (Persian trough weak/medium/deep, high to the west and shallow Cyprus low to the north) is dominant in the summer months. This is the most predictable group. The second group includes three synoptic systems (RST eastern axis, high to the west and high over Israel). This group persists in all the seasons except for the summer. All the other five groups have a smaller predictability. According to the seasons definition (see Section 2), the first order accurate forecast skill decreased with time for all seasons. The major decrease was found in the winter, however, in the transition seasons we found low values of skills too, even after 36 hours of prediction. In summer the first order accurate forecast skill decreases gradually with time. The explanation for the low skills in the first order accurate forecast is probably connected to the coarse resolution.

In order to understand these low values of skills we decided to verify four variables ( $\mathrm{H}, \mathrm{T}, \mathrm{U}$, and $\mathrm{V})$ at 1000 $\mathrm{hPa}$ in three spots over one year (2007). The verification was conducted according to the reanalysis. The total number of the investigated days was 360 . The first spot is located on the Turkey Mountains $\left(37.5^{\circ} \mathrm{N}, 30^{\circ} \mathrm{E}\right)$. The topographic area makes it more difficult for the global models to predict the variables accurately. The second spot is located south to the Cyprus Island $\left(32.5^{\circ} \mathrm{N}, 32.5^{\circ} \mathrm{E}\right)$. This spot represents the Sea and there are less mesoscale influences in this area. The third spot is located near the coastline of Israel $\left(32.5^{\circ} \mathrm{N}, 35^{\circ} \mathrm{E}\right)$. The Sea/Land breeze is a significant mesoscale meteorological phenomenon which global models have difficulties to predict. Tables 3-5 (or Figures 7-9) show the verification results for the Turkey, Mediterranean Sea and the Coastline Spot respectively. According to the verification in all of the three spots (see Appendix 8), the $\mathrm{T}$ and $\mathrm{H}$ variables have a very high skill. The model has difficulties in predicting the $\mathrm{U}$ and $\mathrm{V}$ wind variables in all of the three spots. From the verification we can deduce that a model with very coarse resolution ( $\sim 200 \mathrm{~km})$ has a very low prediction skill of the winds variables for 36 hours (Tables 3-5 or Figures 7-9). The verification explains the low values of skill for the first order accurate forecast even after 12 hours of prediction (Figure 6).

Table 3. Verification (skill) of the daily NCEP geopotential height $(\mathrm{H})$, temperature (T), west-east wind speed (U) and northsouth wind speed $(\mathrm{V})$ in the Turkish Mountains grid point $\left(37.5^{\circ} \mathrm{N}, 30^{\circ} \mathrm{E}\right)$ at $1000 \mathrm{hPa}$. The table represents the skill of forecast in terms of correlation coefficient for 360 days in the year 2007 for the range 12 - 132 hours in an interval of 24 hours according to the semi-objective classification.

\begin{tabular}{ccccccc}
\hline $37.5^{\circ} \mathrm{N}, 30^{\circ} \mathrm{E}$ & $12 \mathrm{~h}$ & $36 \mathrm{~h}$ & $60 \mathrm{~h}$ & $84 \mathrm{~h}$ & 108 & 132 \\
\hline $\mathrm{H}$ & 0.9768 & 0.8264 & 0.6537 & 0.5686 & 0.5382 & 0.5176 \\
$\mathrm{~T}$ & 0.9957 & 0.9707 & 0.9373 & 0.9146 & 0.8803 & 0.8677 \\
$\mathrm{U}$ & 0.8107 & 0.4028 & 0.0989 & 0.0133 & 0.0203 & -0.0166 \\
$\mathrm{~V}$ & 0.9578 & 0.5268 & 0.2202 & 0.1540 & 0.0932 & 0.0172 \\
\hline
\end{tabular}




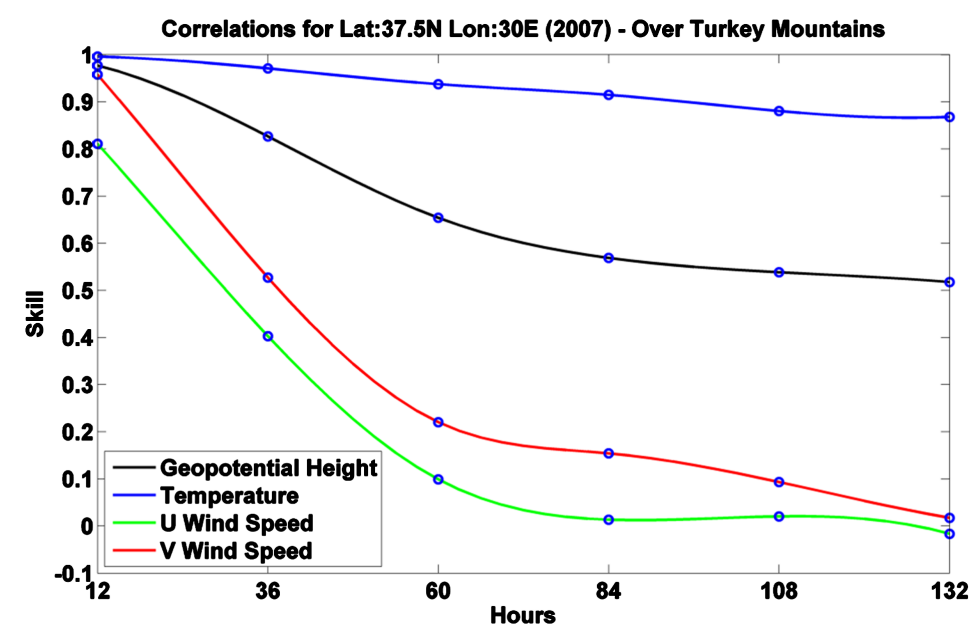

Figure 7. The verification of 4 variables over 2007 for the Turkey mountains spot. Geopotential height [m] (black), temperature $\left[{ }^{\circ} \mathrm{C}\right]$ (blue), Zonal wind speed $[\mathrm{m} / \mathrm{s}]$ (green) and uwind speed $[\mathrm{m} / \mathrm{s}]$ (green) and v-wind (red).

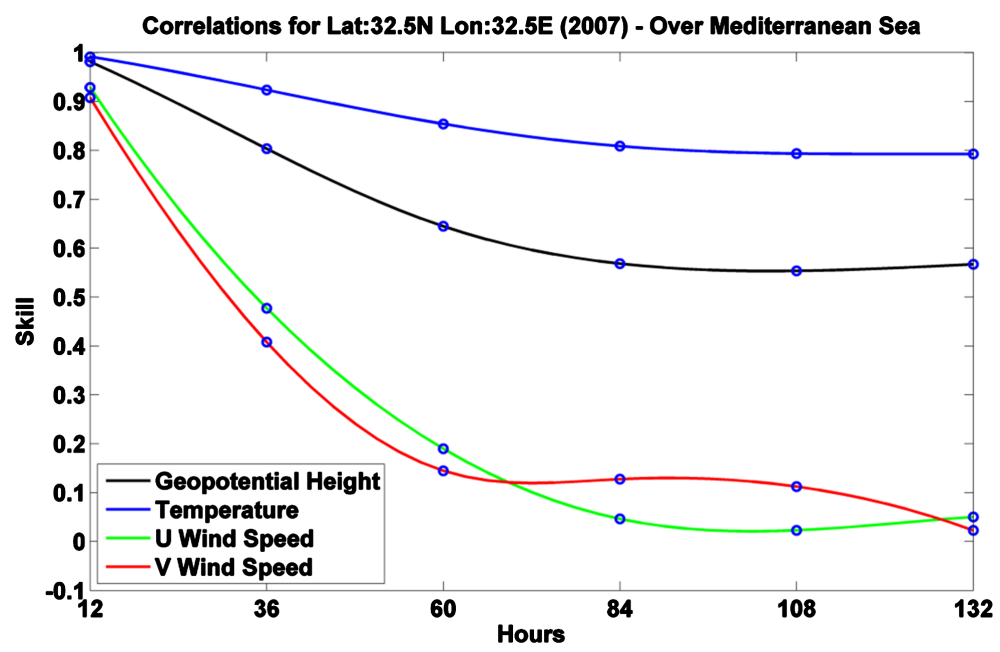

Figure 8. The same as Figure 7, but over the Mediterranean Sea.

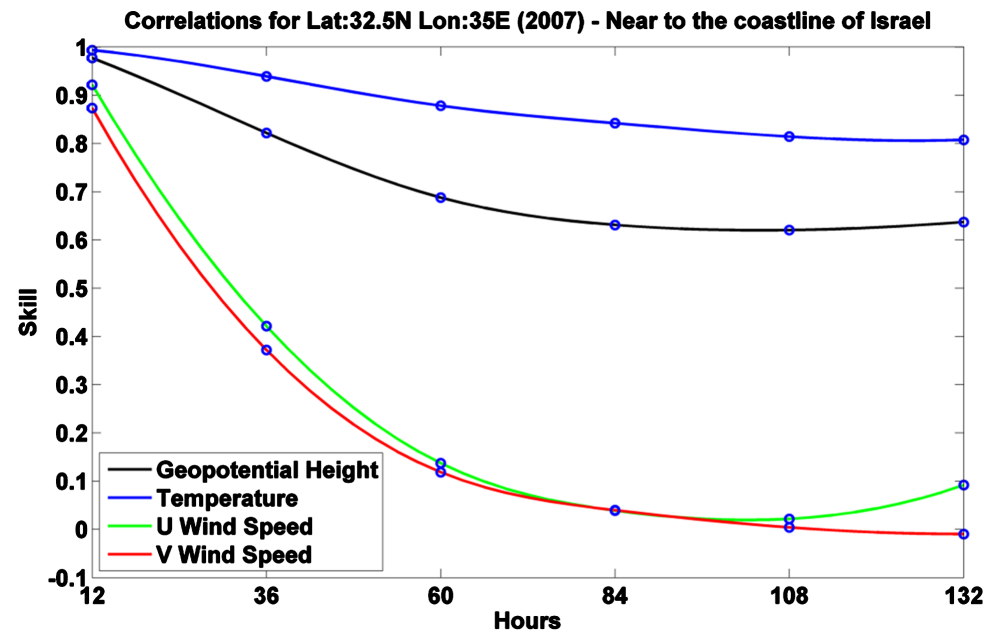

Figure 9. The same as Figure 7, but near to the coastline of Israel. 
Table 4. As in Table 3 but for the Mediterranean Sea grid point $\left(32.5^{\circ} \mathrm{N}, 32.5^{\circ} \mathrm{E}\right)$.

\begin{tabular}{ccccccc}
\hline $32.5^{\circ} \mathrm{N}, 32.5^{\circ} \mathrm{E}$ & $12 \mathrm{~h}$ & $36 \mathrm{~h}$ & $60 \mathrm{~h}$ & $84 \mathrm{~h}$ & $108 \mathrm{~h}$ & $132 \mathrm{~h}$ \\
\hline $\mathrm{H}$ & 0.9812 & 0.8031 & 0.6445 & 0.5682 & 0.5534 & 0.5669 \\
$\mathrm{~T}$ & 0.9913 & 0.9235 & 0.8539 & 0.8084 & 0.7933 & 0.7924 \\
$\mathrm{U}$ & 0.9287 & 0.4771 & 0.1897 & 0.0461 & 0.0229 & 0.0502 \\
$\mathrm{~V}$ & 0.9078 & 0.4078 & 0.1446 & 0.1274 & 0.1123 & 0.0226 \\
\hline
\end{tabular}

Table 5. As in tables but for the north coastline of Israel grid point $\left(32.5^{\circ} \mathrm{N}, 35^{\circ} \mathrm{E}\right)$.

\begin{tabular}{ccccccc}
\hline $32.5^{\circ} \mathrm{N}, 35^{\circ} \mathrm{E}$ & $12 \mathrm{~h}$ & $36 \mathrm{~h}$ & $60 \mathrm{~h}$ & $84 \mathrm{~h}$ & $108 \mathrm{~h}$ & $132 \mathrm{~h}$ \\
\hline $\mathrm{H}$ & 0.9770 & 0.8218 & 0.6877 & 0.6310 & 0.6203 & 0.6370 \\
$\mathrm{~T}$ & 0.9935 & 0.9390 & 0.8781 & 0.8419 & 0.8141 & 0.8073 \\
$\mathrm{U}$ & 0.9217 & 0.4212 & 0.1370 & 0.0388 & 0.0217 & 0.0917 \\
$\mathrm{~V}$ & 0.8734 & 0.3718 & 0.1185 & 0.0396 & 0.0041 & -0.0097 \\
\hline
\end{tabular}

\section{Summary and Conclusions}

Using the WRF model with a very high resolution to predict meteorological variables of Sdom in the southern DS did not yield good enough forecasts for the surface wind and humidity which were crucial for the evaporation prediction. The complex topography in the DS causes difficulties even to a high-resolution mesoscale model with $\sim 1 \mathrm{~km}$ grid interval. Therefore, the synoptic systems approach was employed here. First, we have found the influence of the synoptic systems on the evaporation, temperature, wind speed and relative humidity in Sdom based on a monthly scale. The semi-objective prediction (reforecast) of synoptic systems was verified by the reanalysis during 2006-2009. From previous study we know that some of the synoptic systems are very difficult to predict. For example, it is difficult to accurately predict the evaporation when the axis of the Red Seatrough is located over the EM. Another example is the depth of a Persian trough (weak, medium or high). Therefore, the method of clustering the synoptic systems into several groups was adopted. This new method works through assuming that the influence of the different synoptic systems in each class on the average daily evaporation and temperature is similar. This was entitled as the "Cluster accurate forecast" and it has improved the skill of the prediction. The predictions were divided into three groups: the first order accurate forecast, the cluster accurate forecast and the inaccurate forecast. The sum of the "first order accurate forecasts" and the "cluster forecast" provides the total accuracy. The success after 12 hours was about 80\%. After 36 hours the success dropped to $\sim 70 \%$. And, from $60-132 \mathrm{~h}$ the total accurate forecast was stabilized at $\sim 60 \%$.

In order to explain the low values of skill in the "first order accurate forecast" (after 12 hours the skill was approximately equal to $\sim 56 \%$ and approximately equal to $\sim 20 \%$ after 132 hours) three points in the region based on the GFS grids forecasts were evaluated. In these points the verification was tested for 2007. The model can predict the temperature and the geopotential height variables for these three points very well. However, the model cannot predict the wind variables (U and V) sufficiently. Therefore, it can be concluded that the coarse resolution is the reason for the low values of skills in the "first order accurate forecast".

Employing the new version of the GFS model with a better resolution may improve the results. However, in this case, we will need to classify the synoptic systems again according to a new version with new grids points. In addition, collection of climatology data from Sdom from 2007 until present will improve the connection between the synoptic systems and the average meteorological variables (evaporation, temperature, wind speed and relative humidity) of Sdom. Moreover, achievement of better results in mesoscale models outputs, similar to the one we used, can lead to more successful ways to predict (of predicting) the evaporation. The method presented here is a first attempt to predict meteorological parameters by using a synoptic classification approach in the DS area where even high-resolution mesoscale modeling forecasts are not very successful.

\section{Acknowledgements}

We wish to thank the Dead-Sea Works that supported this research. The German Helmholtz Association is 
gratefully acknowledged for partly funding the finalization of this project within the Virtual Institute DESERVE (Dead Sea Research Venue) under contract number VH-VI-527. Thanks also to the Israel Meteorological Service (IMS) for supplying the observations of Sdom station. We thank Barry Lynn for supplying us with results from the WRF model.

\section{References}

[1] Hodak, E., Gottlieb, A.B., Segal, T., Politi, Y., Maron, L., Sulkes, J. and David, M. (2003) Climatotherapy at the Dead Sea Is a Remittive Therapy for Psoriasis: Combined Effects on Epidermal and Immunologic Activation. Journal of the American Academy of Dermatology, 49, 451-457. http://dx.doi.org/10.1067/S0190-9622(03)00916-2

[2] Ashbel, D. (1939) The Influence of the Dead Sea on the Climate of Its Neighborhood. Quarterly Journal of the Royal Meteorological Society, 115, 185-194.

[3] Bitan, A. (1974) The Wind Regime in the North-West Section of the Dead-Sea. Archiv für Meteorologie, Geophysik und Bioklimatologie, Serie B, 22, 313-335. http://dx.doi.org/10.1007/BF02246585

[4] Bitan, A. (1977) The Influence of the Special Shape of the Dead Sea and Its Environment on the Local Wind System. Archiv für Meteorologie, Geophysik und Bioklimatologie, Serie B, 24, 283-301. http://dx.doi.org/10.1007/BF02263460

[5] Alpert, P., Shafir, H. and Issahary, D. (1997) Recent Changes in the Climate at the Dead Sea-A Preliminary Study. Climatic Change, 37, 513-537. http://dx.doi.org/10.1023/A:1005330908974

[6] Shafir, H. and Alpert, P. (2011) Regional and Local Climatic Effects on the Dead-Sea Evaporation. Climatic Change, 105, 455-468. http://dx.doi.org/10.1007/s10584-010-9892-8

[7] Alpert, P., Cohen, A., Neumann, J. and Doron, E. (1982) A Model Simulation of the Summer Circulation from the Eastern Mediterranean Past Lake Kinneret in the Jordan Valley. Monthly Weather Review, 100, 994-1006. http://dx.doi.org/10.1175/1520-0493(1982)110<0994:AMSOTS>2.0.CO;2

[8] Shafir, H., Jin, F., Lati, Y., Cohen, M. and Alpert, P. (2008) Wind Channeling by the Dead-Sea Wadis. The Open Atmospheric Sciences Journal, 2, 139-152. http://dx.doi.org/10.2174/1874282300802010139

[9] Alpert, P. and Eppel, A. (1985) A Proposed Index for Mesoscale Activity. Journal of Climate and Applied Meteorology, 24, 472-480. http://dx.doi.org/10.1175/1520-0450(1985)024<0472:APIFMA >2.0.CO;2

[10] Stanhill, G. (1994) Changes in the Rate of Evaporation from the Dead Sea. International Journal of Climatology, 14, 465-471. http://dx.doi.org/10.1002/joc.3370140409

[11] Cohen, S. and Stanhill, G. (1996) Contemporary Climate Change in the Jordan Valley. Journal of Applied Meteorology, 35, 1051-1958. http://dx.doi.org/10.1175/1520-0450(1996)035<1051:CCCITJ>2.0.CO;2

[12] Alpert, P., Osetinsky, I., Ziv, B. and Shafir, H. (2004) Semi-Objective Classification for Daily Synoptic Systems: Application to the Eastern Mediterranean Climate Change. International Journal of Climatology, 24, 1001-1011. http://dx.doi.org/10.1002/joc.1036

[13] Banimahd, S.A. and Zand-Parsa, S.H. (2013) Simulation of Evaporation, Coupled Liquid Water, Water Vapor and Heat Transport through the Soil Medium. Agricultural Water Management, 130, 168-177. http://dx.doi.org/10.1016/j.agwat.2013.08.022

[14] Teng, J.D., Yasufuku, N., Liu, Q. and Liu, S.Y. (2014) Experimental Evaluation and Parameterization of Evaporation from Soil Surface. Natural Hazards, 73, 1405-1418. http://dx.doi.org/10.1007/s11069-014-1138-Z

[15] Martano, P. (2015) Evapotranspiration Estimates over Non-Homogeneous Mediterranean Land Cover by a Calibrated “Critical Resistance” Approach. Atmosphere, 6, 255-272. http://dx.doi.org/10.3390/atmos6030255

[16] Ganor, E., Osetinsky, I., Stupp, A. and Alpert, P. (2010) Increasing Trend of African Dust, over 49 Years, in the Eastern Mediterranean. Journal of Geophysical Research, 115, Article ID: D07201. http://dx.doi.org/10.1029/2009jd012500

[17] Saaroni, H., Ziv, B., Osetinsky, I. and Alpert, P. (2010) Factors Governing the Interannual Variation and the Long-Term Trend of the 850 hPa Temperature over Israel. Quarterly Journal of the Royal Meteorological Society, 136, 305-318. http://dx.doi.org/10.1002/qj.580

[18] Ziv, B., Saaroni, H., Pargament, R. and Alpert, P. (2013) Trends in Rainfall Regime over Israel, 1975-2010, and Their Relationship to Large-Scale Variability. Regional Environmental Change, 14, 1751-1764. http://dx.doi.org/10.1007/s10113-013-0414-X

[19] Saaroni, H., Halfon, N., Ziv, B., Alpert, P. and Kutiel, H. (2010) Links between the Rainfall Regime in Israel and Location and Intensity of Cyprus Lows. International Journal of Climatology, 30, 1014-1025.

[20] Yuval, D., Broday, M. and Alpert, P. (2012) Exploring the Applicability of Future Air Quality Predictions Based on Synoptic System Forecasts. Environmental Pollution, 166, 65-74. http://dx.doi.org/10.1016/j.envpol.2012.03.010 
[21] Skamarock, W.C. and Coauthors (2008) A Description of the Advanced Research WRF Version 2. NCAR Tech Note NCAR/TN-475+STR, 113 p.

[22] Allen, R.G., Pereira, L.S., Raes, D. and Smith, M. (1998) Crop Evapotranspiration: Guidelines for Computing Crop Water Requirements. FAO Irrigation and Drainage Paper No.56, Rome, 300 p.

[23] Rimmer, A., Samuels, R. and Lechinsky, Y. (2009) A Comprehensive Study across Methods and Time Scales to Estimate Surface Fluxes from Lake Kinneret, Israel. Journal of Hydrology, 379, 181-192. http://dx.doi.org/10.1016/j.jhydrol.2009.10.007

[24] Branch, O., Warrach-Sagi, K., Wulfmeyer, V. and Cohen, S. (2014) Simulation of Semi-Arid Biomass Plantations and Irrigation Using the WRF-NOAH Model-A Comparison with Observations from Israel. Hydrology and Earth System Sciences (HESS), 18, 1761-1783. http://dx.doi.org/10.5194/hess-18-1761-2014

[25] Alpert, P., Osetinsky, I., Ziv, B. and Shafir, H. (2004) A New Season's Definition Based on the Classified Daily Synoptic Systems: An Example for the Eastern Mediterranean. International Journal of Climatology, 24, 1013-1021. http://dx.doi.org/10.1002/joc.1037

[26] Alpert, P. and Ziv, B. (1989) The Sharav Cyclone-Observations and Some Theoretical Considerations. Journal of Geophysical Research, 94, 18495-18514. http://dx.doi.org/10.1029/JD094iD15p18495

[27] Hamill, T.M., Whitaker, J.S. and Mullen, S.L. (2006) Reforecasts: An Important Dataset for Improving Weather Predictions. Bulletin of the American Meteorological Society, 87, 33-46. http://dx.doi.org/10.1175/BAMS-87-1-33 


\section{Appendix}

Appendix 1. The 19 synoptic systems over the E. Mediterranean and their acronyms according to [12].

\begin{tabular}{ccc}
\hline Code $^{*}$ & Name in English & Short Name \\
\hline 1 & Red Sea Trough with the Eastern axis & RSTe \\
2 & Red Sea Trough with the Western axis & RSTc \\
3 & Red Sea Trough with the Central axis & PT-W \\
4 & Persian Trough (Weak) & PT-M \\
5 & Persian Trough (Medium) & PT-D \\
6 & Persian Trough (Deep) & He \\
7 & High to the East & Hw \\
8 & High to the West & Hn \\
9 & High to the North & He-D \\
10 & High over Israel (Central) & CLs-D \\
11 & Low to the East (Deep) & CLs-S \\
12 & Cyprus Low to the South (Deep) & CLn-D \\
13 & Cyprus Low to the South (Shallow) & CLn-S \\
14 & Cyprus Low to the North (Deep) & Lw \\
15 & Cyprus Low to the North (Shallow) & Le-S \\
16 & cold Low to the West & SLw \\
19 & Low to the East (Shallow) & SLc \\
\hline
\end{tabular}

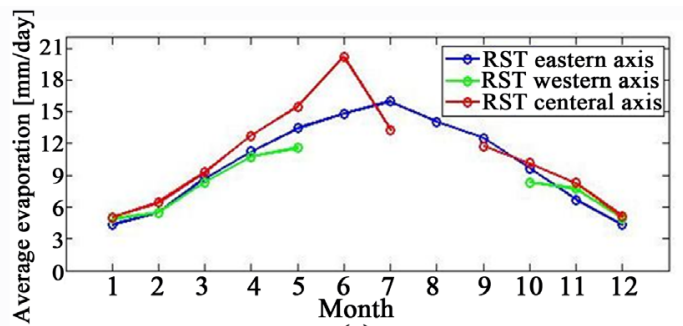

(a)

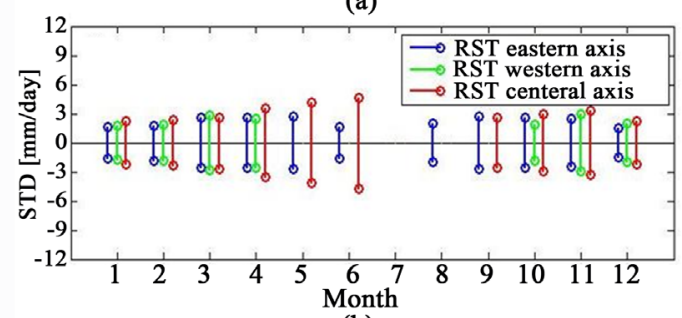

(b)

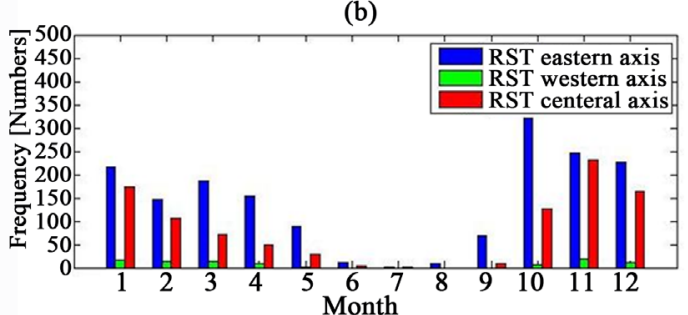

(c)

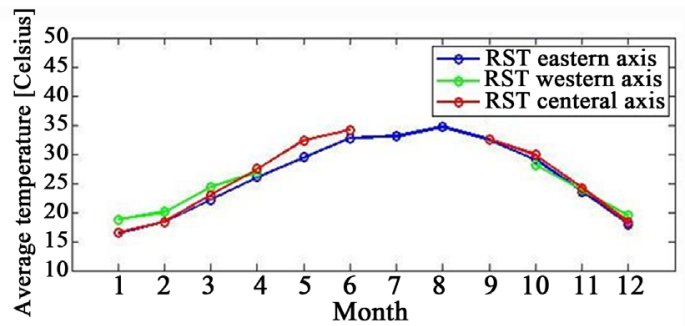

(d)

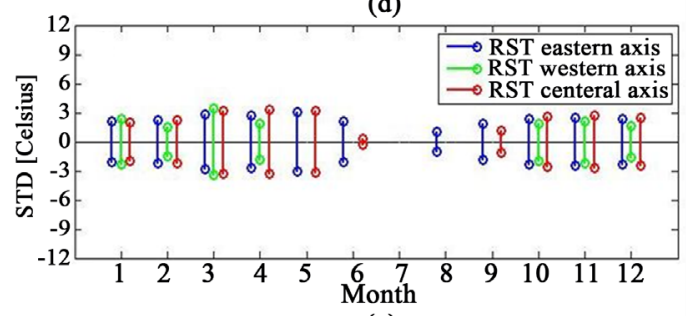

(e)

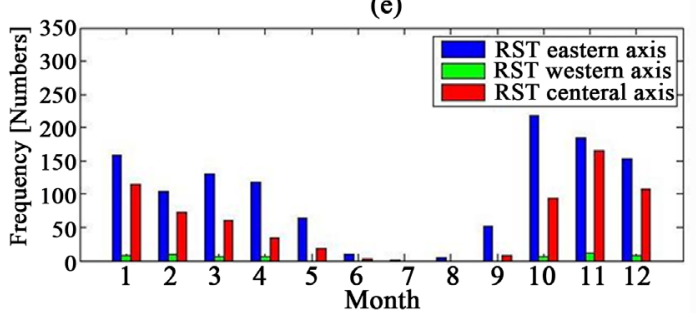

(f)

Appendix 2. The comparison between all RST systems, eastern axis (blue), western axis (green) and central axis (red). The results are based on observations from the period (1964-2006). (a) average daily evaporation (mm/day); (b) standard deviation (std) of evaporation (mm/day); (c) the frequency; (d) average daily temperature $\left({ }^{\circ} \mathrm{C}\right)$; (e) standard deviation (std) of temperature $\left({ }^{\circ} \mathrm{C}\right)$; (f) the frequency. The changes in frequency between $(\mathrm{e})$ and (f) are related to the available data from Sdom. 


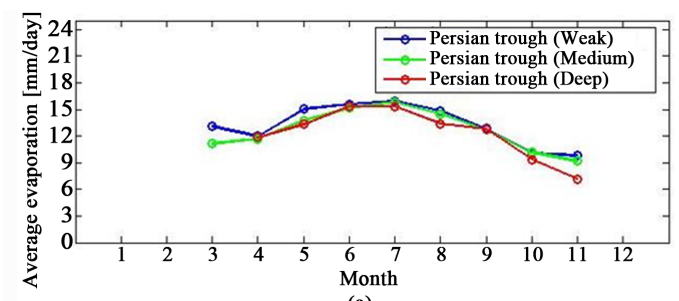

(a)

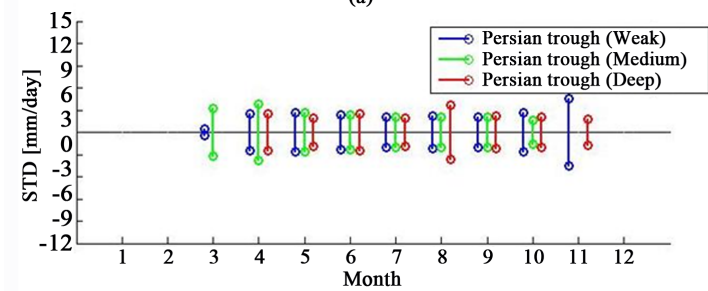

(b)

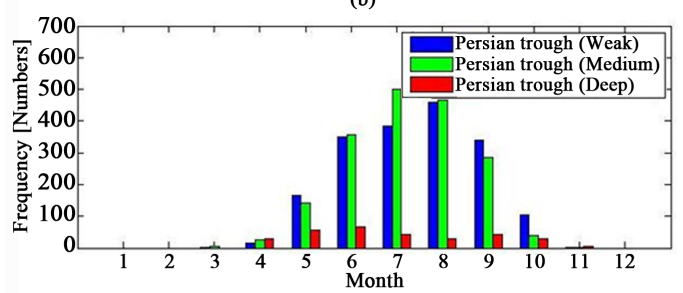

(c)
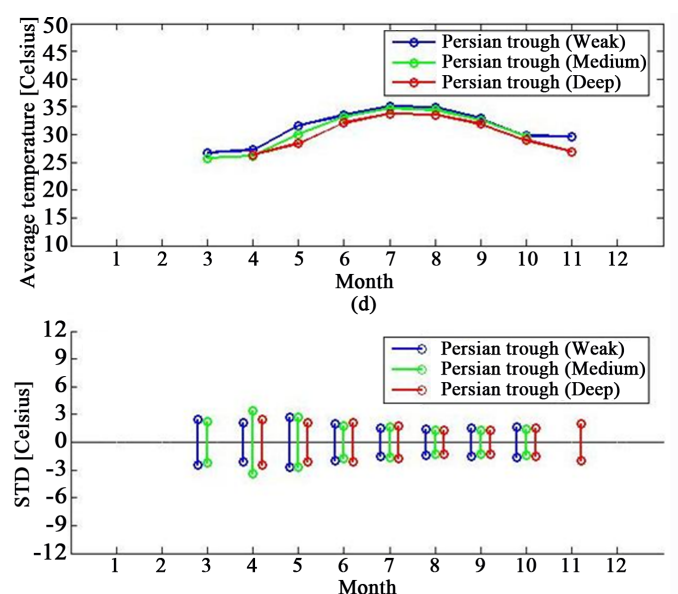

(e)

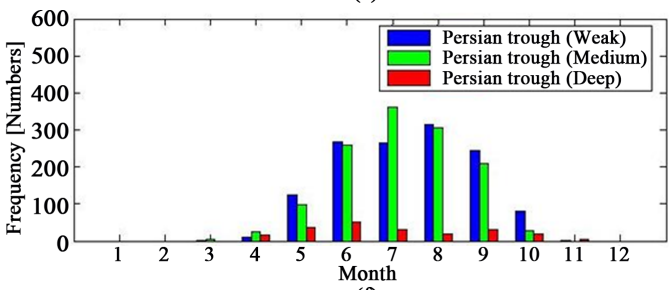

(f)

Appendix 3. The comparison between all Persian trough systems, weak (blue), medium (green) and deep (red). The results are based on observations from the period (1964-2006). (a) average daily evaporation (mm/day); (b) standard deviation (std) of evaporation (mm/day); (c) the frequency; (d) average daily temperature $\left({ }^{\circ} \mathrm{C}\right)$; $(\mathrm{e})$ standard deviation $(\mathrm{std})$ of temperature $\left({ }^{\circ} \mathrm{C}\right)$; (f) the frequency. The changes in frequency between (e) and (f) are related to the available data from Sdom.

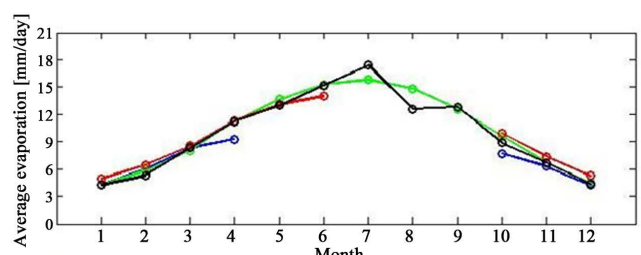

$\rightarrow$-High to the East -0 -High to the West -0 -High to the North $\rightarrow$ High over Israel

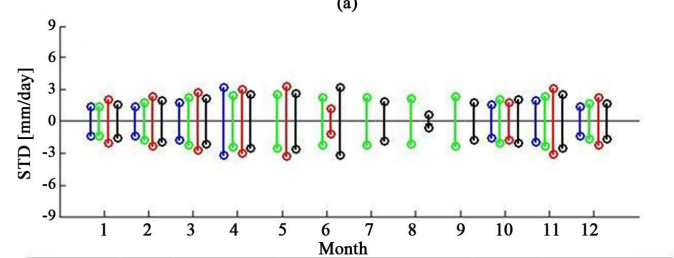

$\longrightarrow$ High to the East - High to the West $\longrightarrow$ High to the North $\rightarrow$ High over Israel

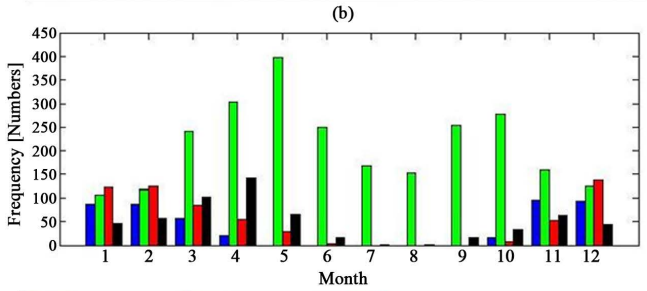

High to the East $\square$ High to the West $\square$ High to the North $\square$ High over Israel

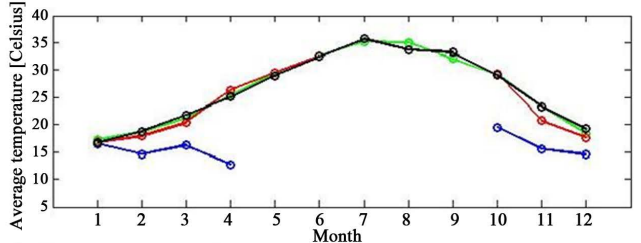

$\rightarrow$-High to the East -0 -High to the West -0 -High to the North - -High over Israel
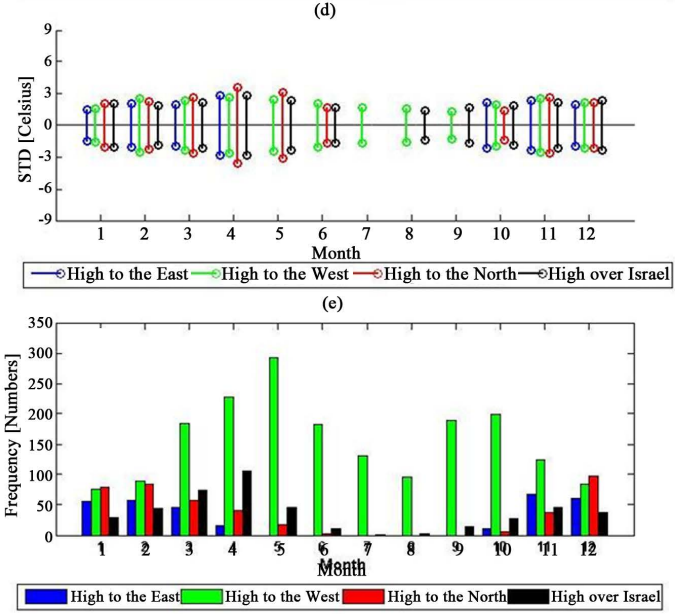

(f)

Appendix 4. The comparison between all highs, east (blue), west (green), north (red) and over Israel (black). The results are based on observations from the period (1964-2006). (a) average daily evaporation (mm/day); (b) standard deviation (std) of evaporation (mm/day); (c) the frequency; (d) average daily temperature $\left({ }^{\circ} \mathrm{C}\right)$; (e) standard deviation (std) of temperature $\left({ }^{\circ} \mathrm{C}\right)$; (f) the frequency. The changes in frequency between (e) and (f) are related to the available data from Sdom. 

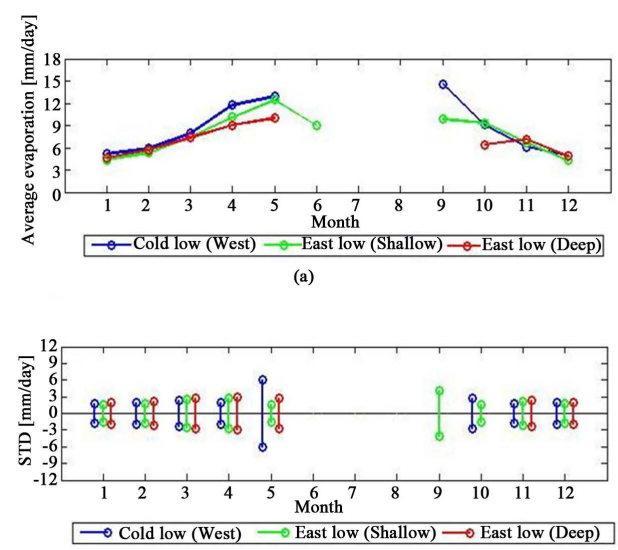

(b)

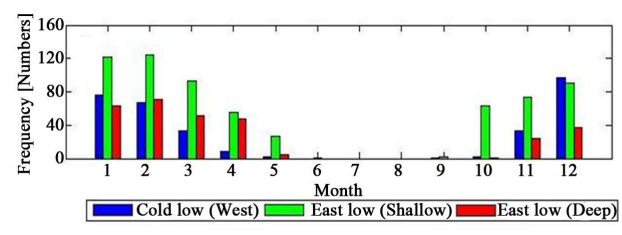

(c)
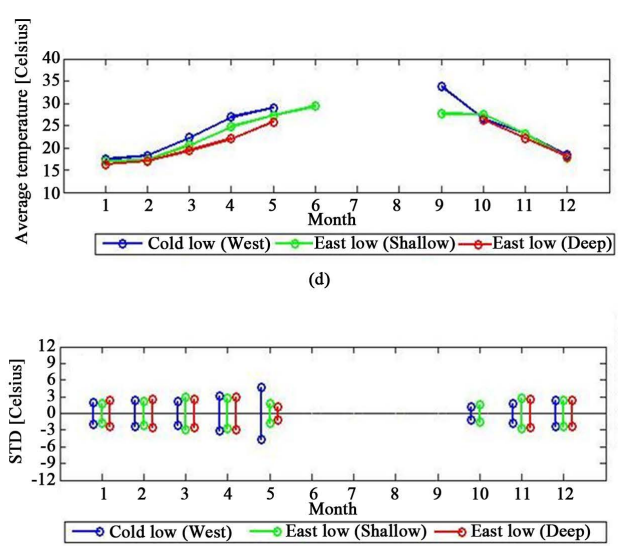

(e)

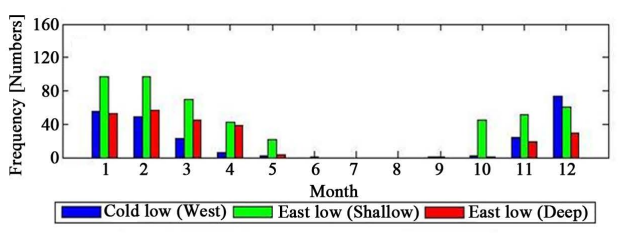

(f)

Appendix 5. The comparison between all lows, cold-west (blue), shallow-east (green) and deep-east (red). The results are based on observations from the period (1964-2006). (a) average daily evaporation (mm/day); (b) standard deviation (std) of evaporation (mm/day); (c) the frequency; (d) average daily temperature $\left({ }^{\circ} \mathrm{C}\right)$; (e) standard deviation (std) of temperature $\left({ }^{\circ} \mathrm{C}\right)$; (f) the frequency. The changes in frequency between (e) and (f) are related to the available data from Sdom.

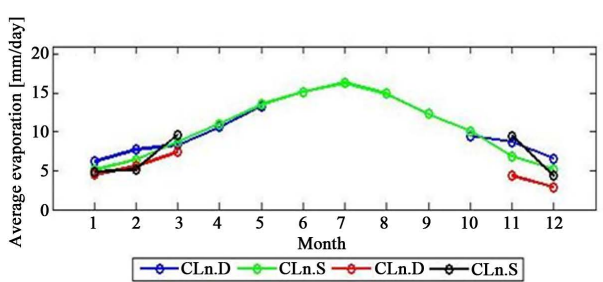

(a)

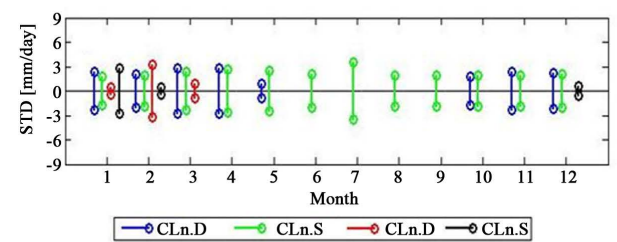

(b)

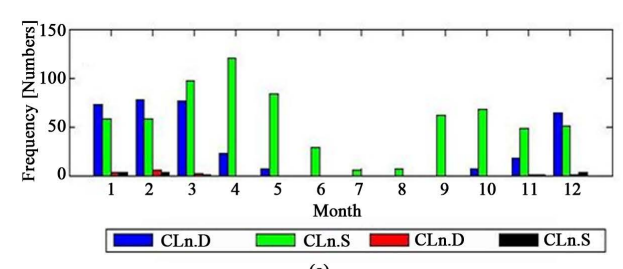

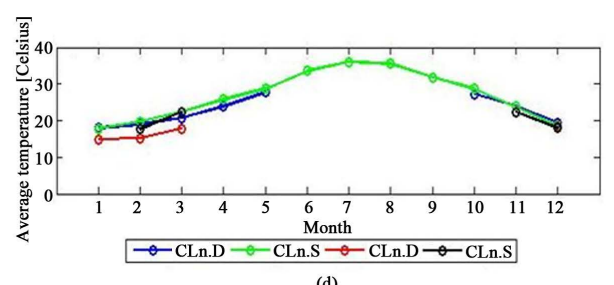

(d)
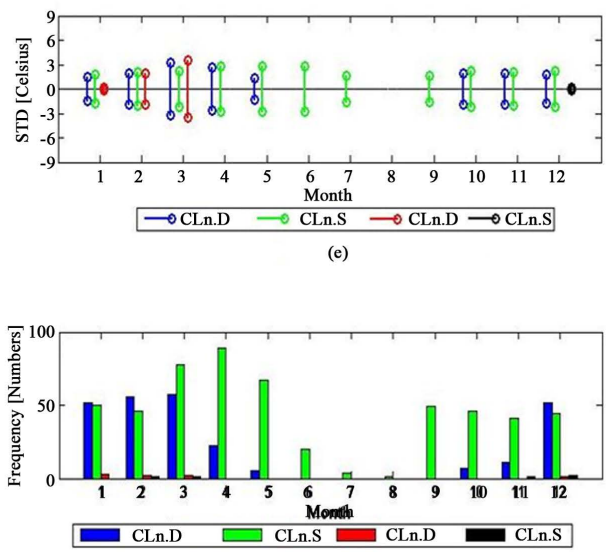

(f)

Appendix 6. The comparison between all Cyprus lows, deep-north (blue), shallow-north (green), deep-south (red) and shallow-south (black). The results are based on observations from the period (1964-2006). (a) average daily evaporation (mm/ day); (b) standard deviation (std) of evaporation (mm/day); (c) the frequency; (d) average daily temperature ( ${ }^{\circ} \mathrm{C}$ ); (e) standard deviation (std) of temperature $\left({ }^{\circ} \mathrm{C}\right)$; (f) the frequency. The changes in frequency between (e) and (f) are related to the available data from Sdom. 


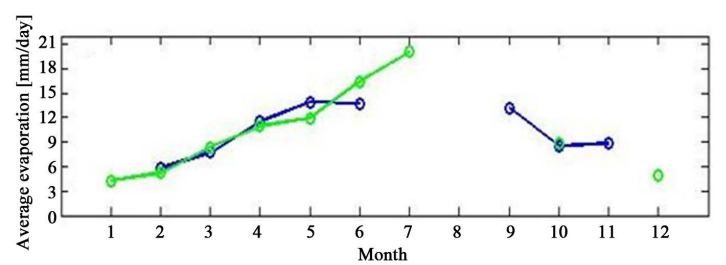

$\multimap$ Sharav low (Center) $\rightarrow-$ Sharav low (West)

(a)

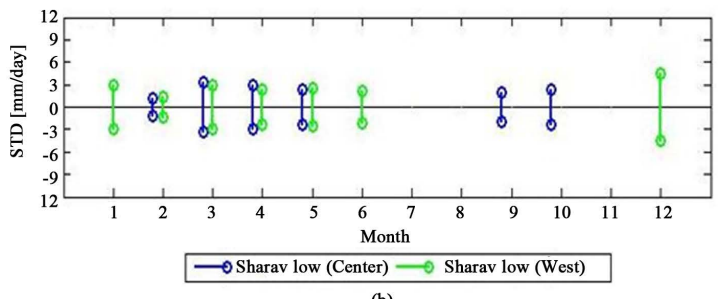

(b)

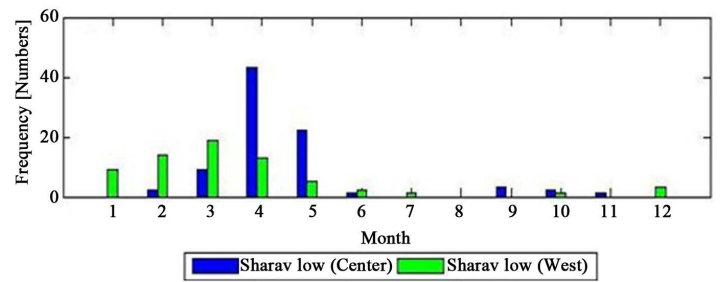

(c)

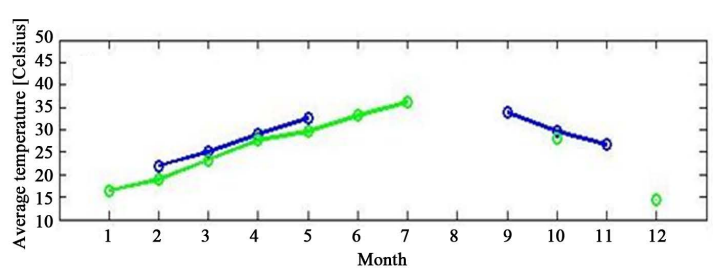

$\multimap$ Sharav low (Center) $\rightarrow-$ Sharav low (West)
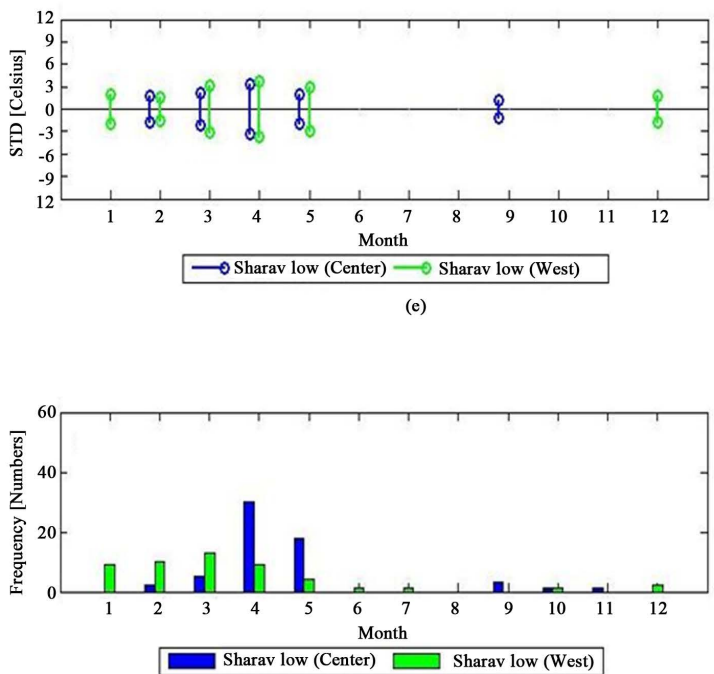

(f)

Appendix 7. The comparison between all Sharav lows, center (blue) and west (green). The results are based on observations from the period (1964-2006). (a) average daily evaporation (mm/day); (b) standard deviation (std) of evaporation (mm/day); (c) the frequency; (d) average daily temperature $\left({ }^{\circ} \mathrm{C}\right)$; (e) standard deviation (std) of temperature $\left({ }^{\circ} \mathrm{C}\right)$; (f) the frequency. The changes in frequency between (e) and (f) are related to the available data from Sdom.

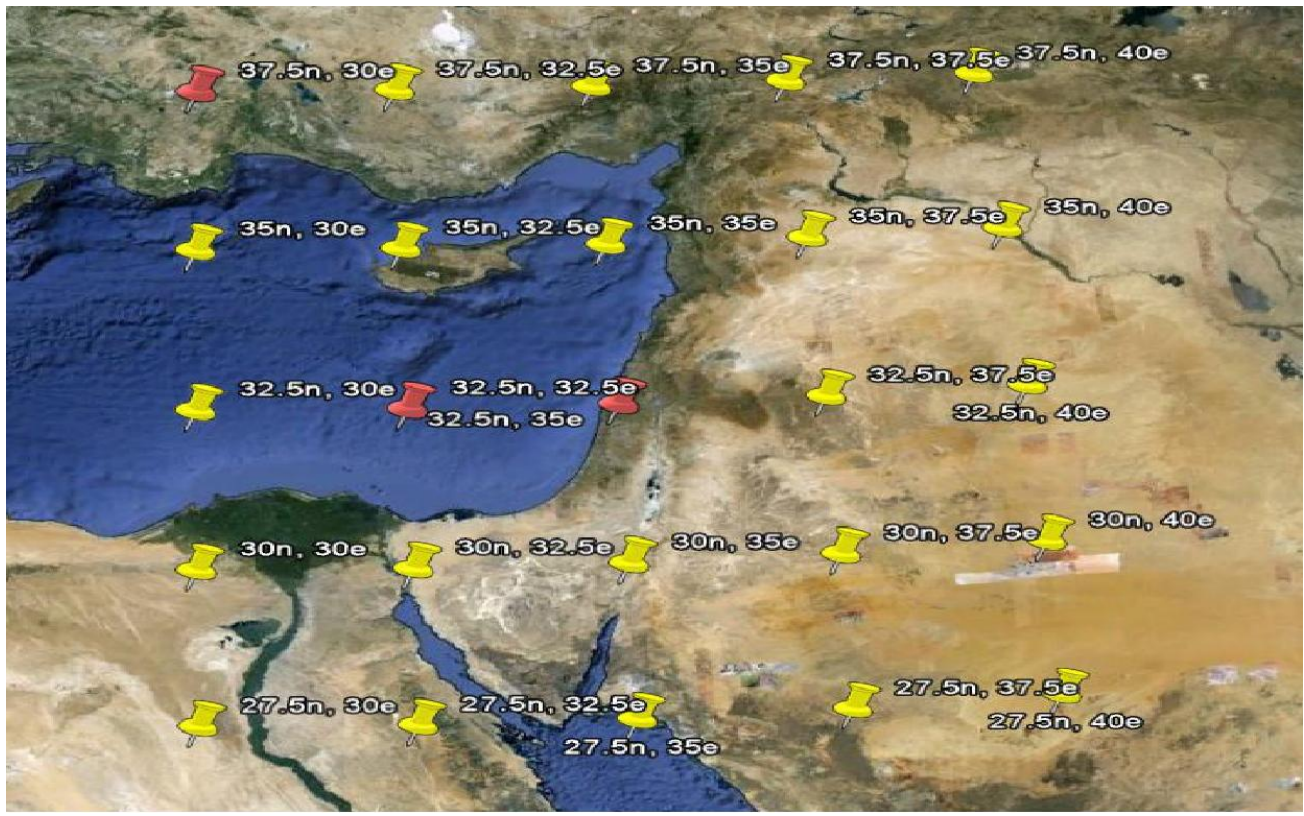

Appendix 8. The 25 grid points employed for the objective synoptic systems classification over the EM [12]. The verification spots are marked in red (see Tables 3-5 and Figures 7-9). 